Cite as: Laursen M and Killen C P, (2019), "Programming for holistic value creation: Collaboration, coordination, and perception", International Journal of Managing Projects in Business. Vol. 12 No. 1, pp. 71-94.

https://doi.org/10.1108/IJMPB-01-2017-0009

\title{
Programming for holistic value creation: \\ Collaboration, coordination, and perception
}

\author{
Markus Laursen*, and Catherine P. Killen ** \\ * Aarhus University, Denmark, Department of Management \\ ** University of Technology Sydney, Faculty of Design, Architecture and Building
}

\section{Programming for holistic value creation: Collaboration, coordination, and perception}

\begin{abstract}
Purpose This study holistically explores value creation approaches in a program of cultural projects to inform the practices of project/program management in both public and private sectors.

Design/methodology/approach The literature on project, program and portfolio value creation informs a case study conducted with engaged scholarship research methods.

Findings Three themes of value creation are revealed: collaboration, coordination, and perception. Effectuation and causation are both observed, demonstrating that a combination of logics underpins decision making in projects.
\end{abstract}

Research limitations/implications The results are based on a single case in a public context. Further research could determine whether the observed value creation themes apply more generally, and explore more deeply the use of logics associated with entrepreneurship in project decision making.

Practical implications The study reveals several non-commercial aspects of value creation that may play a role across a range of project environments. Practitioners may be able to recognize a wider range of value creation and so better nurture these previously unacknowledged types of value.

Originality/value The study provides new insights on value and decision logic through in-depth analysis of value creation in a program of public projects.

Paper type Research paper

Keywords Value Creation; Program Management; Effectuation; Entrepreneurship; Public Value; ECoC 


\section{Introduction}

This study uses a program in a cultural setting to explore value creation in program and project portfolio activities. The holistic management of a portfolio of projects has long been associated with stronger strategic alignment and higher value in the portfolio. The 'value' created by programs and project portfolios is complex and multi-faceted; however, few studies have investigated program value and most research on project portfolio management (PPM) frameworks focus primarily on financial and commercial value, providing little guidance for the management of programs and portfolios with non-commercial aims such as public value (Benington, 2011; Moore, 1995).

The purpose of this paper is to extend our knowledge about how value is created through multiple projects by exploring a non-commercial program in the public sphere.

A case with non-commercial outcomes has enabled this study to identify types of value that are often overshadowed by financial and commercial metrics in commercial organizations. The findings are relevant to both commercial and non-commercial environments and provide greater understanding about managing the types of value that are created through multiple projects in programs or portfolios. The case study was the European Capital of Culture $(\mathrm{ECoC})$ program in Aarhus, Denmark, a program that created cultural activities and events during 2017. The concept of a one-year celebration of European culture and identity was initiated in 1985 by the European Commission (European Union, 2015). In 2012 Aarhus was designated as the Danish host for the $2017 \mathrm{ECoC}$ (referred to as Aarhus 2017), and a commercial foundation was established to head the delivery and management of this $€ 60.2$ million initiative (Aarhus 2017, 2016). The program was planned to include more than 350 cultural, community consultation, and administration projects, with financial support provided by multiple rounds of funding during 2013-2015. Studying cultural projects enables researchers to observe the creation of a wide range of value types, from the individual to the societal level in areas as diverse as wellbeing and economic value (Crossick and 
Kaszynska, 2016). Culture may also add value to the public sphere by asking difficult questions about society rather than simply giving the public what it values (Benington, 2011).

The research reported in this paper provides a novel link between two different perspectives: program organization - particularly temporary organizations - and entrepreneurship. The findings address the call for such linkages in further research (Kuura et al., 2014). This study draws on the field of entrepreneurship by employing effectuation theory, introduced by Sarasvathy (2001) to explain alternative approaches to decision making in entrepreneurial situations. Effectuation principles have subsequently been applied in project management research (Huff, 2016, Nguyen, 2015, Brettel et al., 2012, Nguyen et al., 2018) and this study suggests that effectuation may have a particular role to play in public and community-based projects. In brief, effectuation principles can be considered the inverse of the traditional rational approaches that underlie common project management approaches - in effectuation theory these rational approaches are said to adopt a 'causal logic.' Such causative approaches focus on creating up-front definitions of project aims and results, focus on return on investment, and promote extensive planning to avoid risks. In contrast, 'effectual logic' supports project evolution based on available resources, allowing for affordable losses, while experimenting and forming partnerships to create opportunities and share risks. This study explores the use of both effectual and causal logic in ECoC decision making.

The next section provides an overview of the research context, the ECoC Aarhus 2017. This is followed by a discussion of the background literature and a description of the methodology. Findings are presented according to three themes for creating value - collaboration, coordination, and perception - and the discussion then turns to the types of value and the types of logic underlying decisions made during the ECoC. Application of the findings to commercial environments, implications for research and practice, and limitations of this study are then discussed. The final section presents the conclusions. 


\section{Aarhus 2017 - European Capital of Culture}

The award of the ECoC for 2017 was intended to provide Aarhus and the surrounding region with a cultural and a capability boost by providing a platform to 'rethink' society on a grand scale (Aarhus 2017, 2012). Aarhus announced their candidacy in 2007 and a project organization was established in 2008 to prepare the bid for the selection process that led to the designation of Aarhus as ECoC in 2012. After 2012 the organization was transformed (Hansen and Laursen, 2015), setting up a commercial foundation funded primarily by state, regional, and municipal funds, with some financial input from foundations and the commercial sector. In a timeline of Aarhus 2017 (Figure 1), the transition from project to program marks a change in character and level of activity in the program organization. The foundation had a board of politicians and professional experts who were ultimately responsible for the ECoC. The foundation operated a secretariat to oversee all aspects of the ECoC, including artistic programming, project co-funding, promotion, fundraising, and a small proportion of events in 2017. Ninety per cent of the projects were selected by the program organization and executed by various cultural institutions and other actors throughout Aarhus and the surrounding region. Other major cultural and sports events were affiliated with the Aarhus 2017 narrative without Aarhus 2017 co-funding these activities.

Figure 1. Timeline of Aarhus 2017

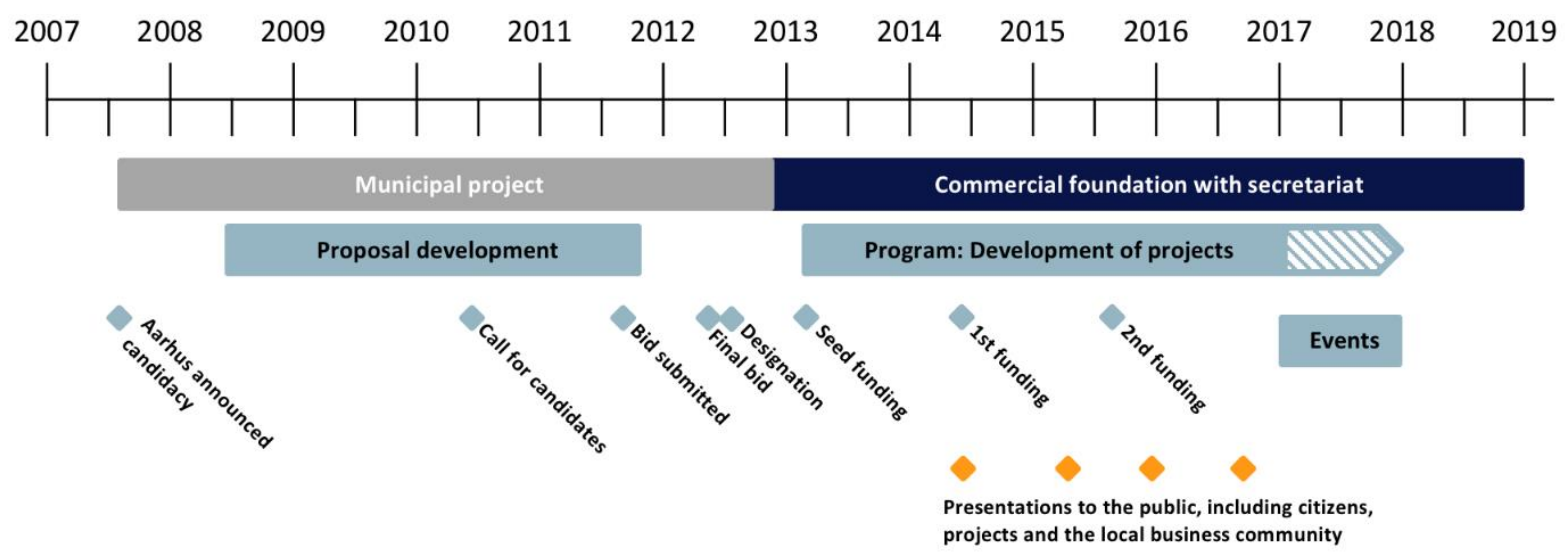


The Aarhus 2017 ECoC was centered on the theme 'Let's rethink,' with three main areas of focus: the city, values, and creativity (Aarhus 2017, 2012). The three areas were complemented by six strategic objectives that provided directions for the development of the ECoC and explicitly stated the anticipated effects and value to be created, for instance:

1: Aarhus 2017 will support the long-term development and also underpin the significance of arts and culture. The cultural program will contribute to a strengthening of the development of a European culture

3: Aarhus 2017 will employ creativity, innovation, knowledge and experimentation to fuel human development and economic growth. (Aarhus 2017, 2012)

Value creation goals were stated as strategic objectives covering six impact areas: Cultural, Image and identity, Economic, Social, Organizational and political, and Governance and funding (Aarhus 2015, 2017).

This paper refers to the group of projects funded under the Aarhus 2017 budget as a 'program,' as identified by Hansen and Laursen (2015), and following the convention used by Näsholm and Blomquist (2015) who studied the 2014 ECoC in Umeå, Sweden. The projects in the program had a shared vision but were run and managed independently from the Aarhus 2017 program organization. The program organization was dissolved during 2018; however, because the projects were independent they were able to extend their activities beyond this time frame.

The high profile of the ECoC led to the initiation of a research project, 'rethinkIMPACTS 2017' (RI2017), to evaluate and learn from Aarhus 2017. RI2017 is a strategic cooperation between Aarhus 2017 and Aarhus University and follows similar ECoC evaluations such as Liverpool 2008 and Umeå 2014 (Garcia et al., 2010; Wåhlin et al., 2016). The study reported in this paper contributes to RI2017 by addressing the lack of knowledge about the management of value in the 
non-commercial sector in the program and portfolio management field. This study focuses on how value is created and managed in a program with a primary focus on public value.

\section{Literature background}

This section reviews the literature regarding long-term value in programs and project portfolios, value creation in a public-sector setting - including the legitimacy of public spending - and concludes with an overview of effectuation literature.

Over time programs have been conceptualized in different ways, from up-scaled projects to project portfolios (Lycett et al., 2004; Maylor et al., 2006; Pellegrinelli, 1997). The focus here is on programs as the coordination of a collection of projects (Pellegrinelli, 2011; Thiry, 2002), which some organizations might label as a 'large project' (Vereecke et al., 2003).

Programs have long been associated with realizing value, but most studies focus on business value (Williams and Parr, 2004; Winter and Szczepanek, 2008), particularly commercial success (Jugdev and Müller, 2005), leading to a suggestion for broader evaluation frameworks (Barclay and OseiBryson, 2009). Commercial value is also emphasized in most portfolio studies and frameworks; however, 'best practice' studies show that a narrow focus on financial value is associated with lower portfolio performance (Cooper et al., 2001; Killen et al., 2008), leading to calls for wider definitions of value and new frameworks that include strategic and longer term aspects (Meskendahl, 2010; Kopmann et al., 2015). However, research on the management of value in projects and portfolios is largely influenced by commercial measures, providing recognition and influence for only a subset of the potential types of value generated by the portfolio. This limits the quality of decisions and provides very little guidance for managing portfolio value in noncommercial environments. 
Project management researchers are beginning to take a more holistic view of value construction (Laursen and Svejvig, 2016). A review of strategic value management in projects and portfolio concluded that there is a 'need to delve deeper and continue to find better ways to comprehensively identify and measure strategic value' (Martinsuo and Killen, 2014, p.56). At the project level Artto et al. (2016) highlighted the value of non-financial aspects such as coordination structures and image, and proposed that new project management approaches are needed to support value creation. Ang et al. (2016) explored the creation of value at a portfolio level, highlighting the wide range of value types perceived by multiple stakeholders and noting that the value created is not always anticipated or articulated, and therefore not adequately measured or included in decision making.

Outside the project management (PM) field value creation is being addressed in ways that might also inform PM research. In PM research related mainly to the for-profit sector value has been defined as a representation of benefit/cost (Laursen and Svejvig, 2016, Morris, 2013), where benefit may be regarded as 'an outcome of a change that is perceived as positive by a stakeholder' (Bradley, 2010), and cost as 'the outlay or expenditure (as of effort or sacrifice) made to achieve an object' (Merriam-Webster, 2016). Thus, the definition of value encompasses both benefits and costs. In practice, however, other terms such as benefit, outcome, and worth (Schryen, 2013) are used interchangeably with value. From this perspective, value is considered subjective and relative to the stakeholder (European Standard 12973-2000, 2000), implying that value for one stakeholder may vary over time. But value has different characteristics in the for-profit and public sectors (Cole and Parston, 2006; Moore, 2013).) The goal and motivation for public organizations is to achieve a social mission by providing ever-improving services (Cole and Parston, 2006), while the goal in the for-profit sector is to maximize shareholder wealth (Moore, 1995). In relation to public spending, Moore (2013) argues that it is the public opinion that justifies investment in areas such as culture. This adopts an instrumental perspective on public value, meaning that public value focuses on what the public values today, but it might be important to also (or instead) focus on long-term public 
value that creates value for future generations (Benington, 2009, 2011). This conceptualization relates to how public spending is legitimized, and legitimacy is known to differ across the lifecycle of an organization; indeed, a startup has to be perceived as legitimate if it is to acquire new resources (Fisher et al., 2016). A short-term organization such as a program may have to follow a similar path of meeting the expectations of different audiences with different norms, standards, and values in order to be perceived as legitimate.

With such a wide range of perspectives on the concept of value, it is unsurprising that views on project and program performance and value creation differ widely. In the public sector, goals are more likely to be related to evaluating the efficiency and effectiveness in achieving a social mission, while in the for-profit sector performance is based largely on the financial bottom line (Moore, 1995). The for-profit sector looks to create the most value by improving the firm's competitive advantage (Prahalad and Hamel, 1990) or by positioning products or services in the market (Porter, 1985), while public sector performance improvement focuses on finding better ways to achieve the social mission (Cole and Parston, 2006; Moore, 2000). Using multiple case studies, Moore (2013) found that techniques from the for-profit sector fell short when applied to the public sector, in that they were unable to address the complexity and the need for balancing goals when achieving a social mission. Despite some differences in the ways various types of organizations view and manage value, both for-profit and public organizations aim to achieve value creation.

In the for-profit sector value creation occurs at various levels, such as micro, mesa and macro (Lepak et al., 2007). Such levels are also evident in the ways that service to citizens (micro level) may create outcomes such as public health that are of value to both the general public and the economy (mesa and macro levels) (Kelly et al., 2002; O'Flynn, 2007). Other common themes in value creation include recognizing the duality of creating and realizing value ( Lepak et al., 2007), value creation as a process of enabling resources (Love et al., 2014; Pang et al., 2014), and value as an outcome of applying capabilities (Barney, 1991). Programs have been discussed as value 
creating systems (Winter and Szczepanek, 2008; Winter et al., 2006) in the understanding that focusing on the customer's customer, or the use of the project's product delivery, means focusing on the outcomes and hence the creation of value. This thinking is reflected in the post- 'New Public Management' wave in creating public value that focuses on the citizen as a shareholder (Horner and Hazel, 2005; Kelly et al., 2002). Some recent studies challenge these normative perspectives on creating public value Bryson et al., 2016), while other authors highlight the central role of collaboration across sectors in the creation of public value (Page et al., 2015).

Collaboration and networking are also emphasized in entrepreneurship studies and reflected in the theory of effectuation. Sarasvathy (2001) observed that entrepreneurial decisions followed a different type of reasoning from the expected causation-based decision making. Effectuation was identified as an inversion of the causation-based reasoning proposed for the creation of new ventures. Effectual logic is based primarily on four principles: (i) 'Available means,' also called the 'bird-in-hand' principle (Sarasvathy, 2008), where goals are driven by the resources that are available; (ii) 'affordable loss,' acknowledging that some losses may be incurred, but promoting decision making to limit potential losses to manageable levels; (iii) 'partnerships,' emphasizing the role of partnering in tackling uncertainty and creating new ventures; and (iv) 'adaptability' or 'leveraging contingencies,' where the unexpected is considered as a new opportunity for developing value (Sarasvathy, 2001). Sarasvathy extended the definition of the principles to include a fifth principle called 'pilot in the plane' that emphasizes the role of the human in shaping the future (Sarasvathy, 2008). Studies in the entrepreneurship field suggest that these four or five principles support decision making and that effectual logic is more likely to be used when by expert entrepreneurs than novices (Read et al., 2009).

However, Sarasvathy's model of effectual logic has been criticized for not meeting traditional quality criteria for a theory (e.g., Arend et al., 2015), particularly that there is insufficient evidence of the explanatory role of the theory and the theory itself does not meet quality criteria in social 
science. Chandler et al. (2011) investigated the dimensions of effectuation in entrepreneurship, and identified effectuation-related constructs of experimentation, affordable loss, and flexibility that show partial alignment with and validation of Sarasvathy's principles. Their study also exposed a causal construct on pre-commitments that co-exists with the effectual approaches. Although effectuation and causation are often presented as opposing logics that could be incompatible, most entrepreneurial decisions employ a combination of both logics (Reymen et al., 2015).

The role of effectuation in environments outside entrepreneurship is also of interest, and new evidence on effectuation theory is coming to light from project-based research, such as studies of project portfolio management (Nguyen, 2015; Nguyen et al., 2018), types of projects (Huff, 2016), and research and development projects (Brettel et al., 2012). Brettel et al. (2012) found that three of the effectuation principles were more likely to be applied when uncertainty was high, but there was little evidence of the use of the 'partnerships' principle. Nguyen et al. (2018) focused on the three principles supported by the Chandler et al. study (available means, affordable loss, and adaptability) in project and portfolio management settings. They found that the level of innovativeness was associated with higher use of affordable loss and adaptability principles, but it did not seem to affect the use of the available means principle. These studies are beginning to shed more light on the roles of effectuation and causation in project environments.

This literature background has emphasised the need to create value through projects - but also has highlighted the complexity of managing value creation across a program of projects with multiple stakeholders. Decision making in such environments is challenging. In some environments an alternative type of decision logic, effectuation, may be useful. This study therefore considered the role of effectuation and causation logics when managing projects in the cultural sector. 


\section{Research methodology}

This study aimed to explore how value creation is practiced in the Aarhus 2017 program. As such, its findings contribute to the research project RI2017 that is formatively evaluating the impacts of the Aarhus 2017 ECoC.

The research was designed as a case study based on qualitative research methodologies (Edmondson and McManus, 2007; Myers, 2009) including interviews (Kvale and Brinkmann, 2009), a research workshop (van de Ven, 2007), participant observation (Spradley, 1980), and document studies (Bowen, 2009). Active dialogue with the Aarhus 2017 organization was part of the collaborative research methodology (Geraldi and Söderlund, 2016; van de Ven, 2007) that used an abductive approach (Dubois and Gadde, 2014; Martela, 2015). This approach involved collecting data with the research question in mind, incorporating theoretical sensitizing concepts such as value creation (Patton, 2002). After coding the interviews, formal theory was applied to inform the theorizing on the basis of the data.

Two kinds of data were used in this study: some were collected specifically, and some were taken from interviews for the RI2017 study that followed Aarhus 2017 from 2013 through 2018. Close collaboration was mutually beneficial, enriching the authors' understanding of the phenomenon and the RI2017 researchers' understanding of project value creation. The focus on impacts was a good fit to the present study, as impacts and long-term value can be considered synonymous.

Interviewees were selected using a purposeful sampling strategy with different criteria across organizational levels. At managerial level all managers relating to programming and promotion activities were selected for interview, including the CEO, program manager, communications manager, and the relevant members of the press, but excluding any managers in charge of administration, staff or volunteers. At the team level, only employees with long-term involvement with Aarhus 2017 were selected; this enabled the researchers to gain comprehensive knowledge of 
the program, which was still being developed. All projects, civil servants, researchers, and others interested in the cultural field were invited to the workshop conducted by one of the authors. One author also participated in RI2017 workshops as an observer, where other participants included top managers in municipalities, cultural actors, and researchers.

\section{Data collection}

Eleven interviews were conducted within the program organization - six conducted by the lead author of this study and seven with the management team as part of the RI2017 evaluation project, as seen in Table 1. All interviews were audio recorded and subsequently transcribed for analysis.

Table 1. Overview of conducted interviews

\begin{tabular}{lllll}
\hline Informant position & $\begin{array}{l}\text { Period affiliated with } \\
\text { Aarhus 2017 }\end{array}$ & $\begin{array}{l}\text { Study } \\
\text { foundation }\end{array}$ & Time of interview & Interview ID \\
\hline CEO & $1.6 .2014-2018$ & RI2017 & June 2014 & CEO_1 \\
CEO & $1.6 .2014-2018$ & RI2017 & Sep. 2014 & CEO_2 \\
CEO & $1.6 .2014-2018$ & RI2017 & Jan. 2015 & CEO_3 \\
CEO & $1.6 .2014-2018$ & RI2017 & May 2015 & CEO_4 \\
CEO & $1.6 .2014-2018$ & Present study & Nov. 2015 & CEO_5 \\
Program director \#2 & $13.4 .2015-2018$ & Present study & Nov. 2015 & PD_1 \\
Program director \#2 & $13.4 .2015-2018$ & RI2017 & Mar. 2016 & PD_2 \\
Communications director & $12.12015-2018$ & Present study & Nov. 2015 & COM \\
Press and event manager & $1.3 .2014-2018$ & Present study & Mar. 2015 & PR \\
Program employee & $2008-2018$ & Present study & Jan. 2015 & PE_1 \\
Program employee & $2009-2015$ & Present study & Nov. 2014 & PE_2 \\
\hline
\end{tabular}

The interviews designed specifically for this study were conducted between November 2014 and November 2015. These interviews were semi-structured. The management-level informants were considered experts, accustomed to answering critical questions and communicating an agenda (Richards, 1996). The interviews conducted as part of the RI2017 research were designed to follow Aarhus on an ongoing basis and were conducted between June 2014 and March 2016. The long time period covered by these interviews and multiple rounds of interviews with the CEO provided 
unique insights into the reasoning for actions, and the increasing trust between the informants and interviewers also provided insights that would have been difficult access by other means.

The research workshop, conducted in June 2015, encouraged participants to document their own value concepts and co-create shared concepts that were recorded on paper and posters. The RI2017 workshop participation took place in May 2014 and November 2016. One author also participated in Aarhus 2017 events, a promotion event in June 2014 for attracting business sponsors, and a public exhibition of the program in April 2015.

Documents collected from the program organization included the final application, also called the 'bid book,' from 2012, the strategic business plan from January 2015 and its updated version in December 2015, a report on legacy planning, and press releases. In addition, more than 200 newspaper articles from Denmark and abroad were collected throughout 2015 and 2016.

\section{Data analysis}

The transcribed interviews were loaded into NVivo for open coding inspired by grounded theory (Charmaz, 2014). The interviews conducted specifically for this study were coded in their entirety. The interviews conducted as part for the general RI2017 were read in full, but only sections relevant to the scope of this paper were coded.

The coding method applied was open coding using gerunds as codes, and thereby focusing on actions (Charmaz, 2014). The coding took place after the conclusion of all the interviews, with 709 codes applied to the interview data. Documents and field notes also served as background information for the coding, and for input to memos that were written during data collection and analysis and were then applied to explore new avenues during data collection. The background information qualified the statements made by informants, by elaborating, supporting or, at times, contrasting with statements made during interviews. 
The open codes were subsequently grouped into categories, starting with the most populated codes. Each category was a group of similar codes with meaningful concepts. The coding resulted in nine categories, from which emerged three themes (overarching connectors of these concepts). Table 2 illustrates how codes related to categories that supported the three themes.

Table 2. Coding and categorizing

\begin{tabular}{|c|c|c|}
\hline Themes & Categories & Code examples \\
\hline \multirow[t]{4}{*}{ Collaboration } & Establishing networks & Unwillingly cooperating \\
\hline & & Internationalization \\
\hline & Building capabilities & Developing local communities \\
\hline & & Educating municipalities \\
\hline \multirow[t]{8}{*}{ Coordination } & Setting direction & Programming with expertise \\
\hline & & Pulling everything together \\
\hline & Clustering & Inviting tourists \\
\hline & & Creating the extraordinary \\
\hline & Diversification & Diversifying program \\
\hline & & Showing true Danish \\
\hline & Grooming & Programming method \\
\hline & & Developing projects \\
\hline \multirow[t]{6}{*}{ Perception } & Informing & Communicating relevantly \\
\hline & & Informing for monitoring \\
\hline & Engaging & Managing criticism \\
\hline & & Handling timing challenges \\
\hline & Establishing narrative & Telling the story \\
\hline & & Legitimising ECoC \\
\hline
\end{tabular}

\section{Findings: Holistic value creation through a program}

This study identified three primary themes for value creation in managing the program and preparing the ECoC year: collaboration, coordination, and perception. Each of these themes is related to three recognized value types: strategic, transformational, and emergent value. Exploring the themes and types of value illustrates that both effectuation and causation play a role as underlying logics for decision making in the program.

\section{Value in collaboration}

One of the strong benefits of an initiative such as Aarhus 2017 is the creation of collaborative capabilities. The value from collaboration and from the development of networks and new cross- 
organization relations (Granovetter, 1973) was a repeated theme discussed by the interviewees from the Aarhus 2017 program organization. It suggests both transformational and emergent value from executing an ECoC for the individuals and organizations involved.

Establishing networks was highlighted in relationships between individuals, municipalities, and even organizations across EU member states. After Aarhus had announced its candidacy in 2007, the collaboration started with all municipalities in the Central Denmark Region and the Administrative unit for this region preparing the joint bid from 2008 to 2012. It was the first time these municipalities and regional administrative unit had worked together after the municipal structural reform in 2007. Preparing the bid was an open process with many activities until 2012, involving meetings and workshops of both cultural institutions and citizens. In this way, an ECoC has a much higher level of collaboration than other types of cultural initiatives such as a festival. One manager said: 'European Capital of Culture is created often from consensus. It comes often from a broad or very imaginative consultation and that kind of creative brainstorming feed into what people want from it' (CEO_5). Individuals and artists connected through these processes, and all 19 municipalities also formed collaborations. The cultural city councilors collaborated formally through committees and also informally across new geographical spans. The network has an unanticipated development as 'some of the culture managers had to be dragged into this circle ... To the transformation of them realizing that they are the basis for one another. They can help each other, and they have become colleagues' (PE_1). The cultural managers were a showcase for the synergies of collaborating across municipalities and served as inspiration for other managers in the 19 municipalities.

Projects were required to have local, regional, and European dimensions, which included partners from other EU member states. However, not all projects were able establish new connections on their own: 'I think we need to work with the projects to advise, to create the international networks 
and connections, or build the ones they already have.' (CEO_1). Some of the obvious connections made were to other ECoC hosts that the managers knew from the 'ECoC family'.

Another dimension to the establishment of networks was that some employees in the Aarhus 2017 organization were seconded from the regional administrative unit and some municipalities. These individuals contributed to creating a network among the municipalities and the regional organization that remain a legacy of the ECoC. The program organization itself was divided into teams, and the internal collaboration was also a source of value creation. The teams complemented each other in identifying stories that help communicate the narrative of the ECoC (PR).

These networks and identified synergies are expected to exist well beyond the finalization of the 2017 program, facilitating future value creation. This suggests that the value of establishing new relationships may be intrinsic, implying that the value of an initiative such as the ECoC is not only created through the use of the project outputs, as suggested by the instrumental value creation perspective (Winter and Szczepanek, 2008; Winter et al., 2006), but it also has an emergent nature. The networks are also a foundation for building new capabilities.

Building capabilities covers a category where networks and learning are operationalized. The ECoC offers a fast track to gain experience in collaborating with international partners on EU funding applications, as the ECoC is a brilliant platform for marketing oneself and cultural offerings that would not receive much attention in trivial situations. One of the managers said: 'being designated European Capital of Culture gives you a platform for you to present yourself internationally ... it is a platform for promoting Danish culture' (COM). The platform has intrinsic value, but the greatest value is achieved by actually using the platform, for example for promoting urban regeneration projects. Municipalities are often engaged in promoting projects, and engaging in a bid process is a good opportunity for municipalities to gain experience for applying for EU funds. Such experiences form capabilities that support EU funding of future projects, and there are 
rich opportunities for improving these capabilities among Danish municipalities (COM). The level of experience and capabilities with EU funding vary across municipalities, and part of the programming effort is to ensure that the entire region develops strong capabilities in these areas. In this way, the ECoC provides a new avenue for municipalities to access EU funding.

The ECoC was a combination of a locally anchored initiative through Danish managers, seconded employees from Danish public organizations, and international highly skilled managers from the cultural sector. Some of the employees had worked up to ten years with the $\mathrm{ECoC}$, longer than any other area in their careers, and they had brought back experiences and capabilities for hosting cultural programs and major events, as well as facilitating cultural development and EU collaboration. In this way the region's overall capability has increased as a result of the process itself (Laursen, 2018). Value in collaboration is not only in the intended and unanticipated establishment of new networks among people and organizations, but also in the value of boosting organizational capabilities.

\section{Value in coordination}

Coordination of activities to create synergies is at the heart of program management and in this way it brings about a change greater than the sum of all projects. Two significant findings from this study were coordinating for a diverse year-long program where everyone had a defined role, and securing a strong legacy. Thus, coordination was related to both the programming of activities during 2017 and long-term projects, such as the soft city projects that were primarily focused on long-term change and the legacy of Aarhus 2017 (PD_2).

Setting direction means creating a common thread for all projects that were co-funded by the ECoC program organization by having a clear artistic and program direction that guided funding and communication. The overall direction was given by the Aarhus 2017 slogan 'Let's rethink' that the bid book had presented, along with three areas for rethinking: the city, values, and art and 
creativity. The structure of these areas was communicated differently during the programming period, but the areas continued to communicate the direction to projects applying for funding. It was the responsibility of the program organization to make it coherent, as the CEO explained:

So there has to be that kind of professional expertise to pull together what a European Capital of Culture can be, to give it a kind of more homogenous whole for it to have impact ... I think if you're saying 90\% of the projects are external and they are developed by other ideas and other mindsets and other organizations you still need to have some red thread. (CEO_1)

The expertise was provided especially by the CEO and the program director, who both had experience with programming and curating major artistic events.

Diversification was built into the program from the outset, as the program organization had three guiding values: diversity, sustainability, and democracy. Diversification refers to the public's reception, and therefore it was a premise for programming, as stated by the CEO: 'We always wanted to create a program that is open, that is diverse, has different voices in it. That is diverse in not only reflecting different cultures, but the manifold cultures of Denmark; that everyone has their space in that year' (CEO_5). From the outset, there would be room for coordinating a diverse program, as 350 projects and events were predicted in the bid book from 2012 (Aarhus 2012, 2017). These measures were taken to secure not only an enjoyable year of events in 2017 but also to create something valuable that would persist with the citizens in Aarhus and the surrounding region.

An ECoC such as Aarhus 2017 included not only what was in the program, but also projects that were not funded by the ECoC that could contribute to the overall vision. These unofficial, yet complementary, projects may produce more radical content than ECoC funded projects, as one manager asked: 'Why do you want to be official? Why don't you stay unofficial and then you can do whatever you like' (PD_1). Through these associated projects, the experience and capabilities of the 
program management team contributed to developing the local artistic community, and thereby making Aarhus 2017 a driver for capability development. Overall, projects adhering to the purpose of rethinking were treated positively, in line with the diversity and democracy values.

Clustering refers to timing the program, both on a small scale and overall. The program organization coordinated and put together the program for the benefit of tourists by programming two or three highly interesting events together: 'So people want to come to Aarhus for a weekend. And from that we bring them right into the region to see all the other projects. We give them the opportunity to do that' (CEO_3). This form of coordination would allow for more value to both tourists and the projects.

On an overall scale the program was divided into four main seasons, as seen in Table 3, which served as a guide for planning activities during 2017. Each season had one mega event that expected an average of 60,000 participants, and across the program 12 full-moon events were planned, one for every month, each expecting 15,000 participants. This coordinated timeline ensured the year had the right momentum (CEO_4), and the mega events ensured that the program provided something extraordinary: 'What we needed to do is to make sure that we have those really spiky, interesting moments that have two great famous maybe, or very good artists or organizations or cultural engagers working' (CEO_3). The mega events were to be something the participants would remember, similar to the shows at the 2012 Olympic Games in London (CEO_1).

The publications by the program organization clearly show the progression of communicating the program and grouping events throughout the year, from the bid book in 2012 through two strategic business plans in 2015 (January and December) to the program book presented in October 2016. One major change was labelling event categories that gave the program a specific structure (Aarhus 2015, 2017). The structure changed throughout the program, as illustrated in Table 3 . The events 
and activities planned for 2017 covered the past, the present, and the future, with events centered on celebrations, contemplations, and provocations (PD_2).

Table 3. Program structure

\begin{tabular}{|c|c|c|c|c|}
\hline & $\begin{array}{l}\text { Final application. } \\
\text { June } 2012\end{array}$ & $\begin{array}{l}\text { Strategic business plan. } \\
\text { January } 2015\end{array}$ & $\begin{array}{l}\text { Strategic business plan. } \\
\text { December } 2015\end{array}$ & $\begin{array}{l}\text { Our Legacy: A new } \\
\text { beginning. March } \\
2017\end{array}$ \\
\hline $\begin{array}{l}\text { Impact } \\
\text { through }\end{array}$ & $\begin{array}{l}\text { Program structure } \\
\text { Dimension 1: } \\
\text {-Rethink the City } \\
\text {-Rethink Values } \\
\text {-Rethink Creativity } \\
\text { Dimension 2: } \\
\text {-The City \& Citizens } \\
\text {-The European } \\
\text { Dimension } \\
\text { Two crosscutting } \\
\text { program strategies: } \\
\text {-Cultural Infrastructure } \\
\text {-Soft City }\end{array}$ & $\begin{array}{l}\text { Program themes: } \\
\text {-Rethink the City } \\
\text {-Rethink Values } \\
\text {-Rethink Creativity } \\
\text { Crosscutting Concepts: } \\
\text {-Cultural Infrastructure } \\
\text {-Soft City } \\
\text {-The European Dimension } \\
\text {-The City \& Citizens }\end{array}$ & $\begin{array}{l}\text { Three concepts: } \\
\text {-Rethink the city } \\
\text {-Rethink values } \\
\text {-Rethink art and } \\
\text { creativity } \\
\text { Four motivations: } \\
\text {-Cultural -Infrastructure } \\
\text {-Soft City } \\
\text {-The European } \\
\text { Dimension } \\
\text {-The City \& Citizens }\end{array}$ & $\begin{array}{l}\text { Legacy: } \\
\text { Political/organizational } \\
\text { legacy } \\
\text { Program } \\
\text { Legacy of memory } \\
\text { Communications } \\
\text { legacy } \\
\text { Development legacy }\end{array}$ \\
\hline $\begin{array}{l}\text { Structure } \\
\text { of event } \\
\text { and } \\
\text { activities } \\
\text { in } 2017\end{array}$ & & $\begin{array}{l}\text { Themes (12) } \\
\text { Knowledge, history and } \\
\text { cultural heritage (the } \\
\text { memory of the city) } \\
\text { Architecture and urban } \\
\text { spaces (the open and living } \\
\text { city) } \\
\text { Nature, routes and tracks } \\
\text { (cultural landscapes) } \\
\text { Design, technology and } \\
\text { creative businesses (the } \\
\text { digital city and creative } \\
\text { businesses) } \\
\text { Sport, physical activities } \\
\text { and games (the playful city) } \\
\text { Exhibitions (visual art, } \\
\text { sculpture and landscaping) } \\
\text { Film, animation and digital } \\
\text { culture/cross media } \\
\text { Music, sound and sound art } \\
\text { (musical horizons) } \\
\text { Performing arts, dance, } \\
\text { theatre and performance } \\
\text { Debate and literature } \\
\text { Gastronomy and food } \\
\text { Seminars, conferences and } \\
\text { workshops (soft city) }\end{array}$ & $\begin{array}{l}\text { Themes (7) } \\
\text { Liveability } \\
\text { Food and gastronomy } \\
\text { Nature } \\
\text { Sport and play } \\
\text { History } \\
\text { Belief } \\
\text { Generations }\end{array}$ & \\
\hline
\end{tabular}


Grooming projects means showing trust and seeing the potential in less developed projects.

Receiving seed funding or initial funding from the program organization did not guarantee a place in the program. Projects had to show both progression and the ability or potential for delivering quality content for events or other activities in 2017. Thus, the development of projects was a matter of trusting that artists would be able to develop their project (PD_1). At other times the job was to assist in lifting the projects and giving them energy:

We did a quick speed date wordplay to come up with something that is now a very entitling title and actually gave them a lot more energy. They went of the room feeling lifted, and oh yeah we have a title that is much better. So it wasn't that it was a bad project, it's just about helping people repackage those pieces of information or their approach so that they are still lifting. (PD_2)

Thus, aside from ensuring that projects were producing quality content, coordinators also helped projects stay on track (PD_2). The capabilities and funding in a program organization can foster rapid development and transformation given the right circumstances. But a coordinated program also makes it possible to develop a hub and boost local arts communities that might never happen under usual conditions which 'might be building some people up that have certain capacities or not building some people up who do not have the capacities or allowing this group here, who may have capacities to evolve to a point, where they do have capacities' (PD_1). Building capacities was a way to secure the legacy of Aarhus 2017, as the capacity to deliver high quality cultural content will benefit the region for years to come.

Coordination was an ongoing activity, as the projects were funded through three funding pools: seed funding in 2013 for some of the projects that were involved in the development of Aarhus' ECoC bid, and co-funding of projects in 2014 and 2015. More than 100 projects were eventually 
part of the program. Coordination was a matter of intended transformation, where the program could exercise control over funding and direction.

\section{Value in perception}

Perceptions of value can be highly subjective and complex - and for a large and expensive public initiative such as the ECoC, such perceptions are very important as public opinion hinges on justifying public spending (Moore, 2013). Managing the perception of value was a major theme in the findings.

Informing the stakeholders and managing their perceptions provided a basis for the stakeholders to form an opinion about the ECoC content. Any stakeholder can only form an opinion based on what they know, and stakeholder perceptions of value are one way that the delivered value can be determined. Managing stakeholder perceptions is a specific way of managing stakeholders (Toor and Ogunlana, 2010), and one that suggests Aarhus 2017 needed to be visible and associated with positive experiences so the public could form positive opinions about the ECoC (PR). Political sponsors in particular needed to be made aware of the content being delivered, and thus the ECoC provided reports to the political sponsors from local politicians to the EU. The public is a heterogeneous group, the perception of value will always be mixed, and critical voices will hold politicians accountable for the public spending on culture. Similarly, politicians hold the program management accountable for delivering a success defined by the agreed KPIs. Perceptions of value are one way that value can be 'measured'; in the absence of hard measures of the quality of the experience or the impact on the community, both users and the public community at large can form opinions that provide a mirror of the value being proposed by the program or a single project.

Engaging in positive perceptions is related the activation of the media and ensuring excitement about the program at the right time. The program organization needed support from the media and other external stakeholders, as only by the ECoC being visible and associated with positive 
experiences would the public think of the organization positively and perceive that it had met the defined success criteria (PR). The ECoC faced a challenge in the organizational division between beneficiaries and sponsors. Thus, the value for ECoC's beneficiaries needed to be visible to the sponsors, and the ECoC needed to communicate to the public and political stakeholders how projects in the ECoC program were creating value even before 2017. The communications team used both social and traditional media on a weekly basis (PR), and they invited international journalists to Denmark; indeed, around 100 articles about Aarhus 2017 were published in foreign media outlets during 2016 alone.

Any negative press coverage about the ECoC had the potential to spill over to perceptions of value of the entire program's projects. Negative press coverage could have diminished willingness to endorse the ECoC: 'it might have a self-reinforcing effect, because it is impacting a general attitude or it might encourage others to join the choir. That is the reason one should not just lean back and let critique be undisputed, one should try and talk about it when it is unjustified' (PR). The Aarhus 2017 organization sought to encounter negative media coverage and pressure from the public by collaborating very closely on communicating a positive narrative from the outset.

A timing challenge for the ECoC was informing the media and the public well in advance of the events planned to take place during the year - all ECoCs face this challenge. However, advising too far in advance could be counter-productive: 'It's like giving someone a Christmas catalogue in May. It is pointless for us to be saying to them "Okay, here you go. Choose what you want now." Because you are not in the mindset' (CEO_3). The program organization deliberately revealed the program in stages over the course of 2015 and 2016, applying the Hollywood formula with a buildup phase and a climax.

Telling the narrative was an ongoing focus for Aarhus 2017, aiming to make the ECoC interesting and relevant for the public. The narrative was that Aarhus 2017 was broad: 
So it's not just about the arts, although of course it is about arts and creativity, but it's also about sports, food, politics, religion, education and language and all of the that make up who we are in terms of our cultural identity or even our national identity. It is a story of all of those things. (CEO_5)

This narrative was often communicated using storytelling (Fog et al., 2010), and the program organization was quick to put positive news or stories on Facebook to show that value was being delivered even before 2017. The Aarhus 2017 program communicated through various channels, such as directly to the public on social media platforms, where they ensured a diverse and even coverage of the projects. The ECoC has been compared to the Olympic Games. However, one major difference is very important for telling the narrative: the public are familiar with the Olympic Games, but often the ECoC is entirely unknown, making communication potentially difficult. The narrative contributed to communicating to the public, as the slogan about rethinking made it difficult to be specific and everything had to be developed (PR).

Achieving success was important for the political sponsors, enabling them to justify spending more than $€ 50$ million on Aarhus 2017. The sponsors of the ECoC measured the success of Aarhus 2017 through a set of KPIs that captured perceptions from the direct beneficiaries of the program - the citizens and visitors who had the experiences and took part in events. In this way, the perception of value was central to the evaluation of Aarhus 2017, and overall the value in managing perceptions was strategic, especially the increase in international awareness of Aarhus in a branding context.

\section{Dimensions of value}

The three themes for program value creation covered at least three types of value: transformational, emergent, and strategic, associated with the organizational, ecosystems, and societal levels (Ouden, 2012). 
Value in collaboration was unanticipated or emerging, as managers from municipalities now had a common raison d'être in the area of culture. Value in coordination sought to ensure the change and impact would take place as intended through having an overall direction, and this could be labelled as transformational value (Gregor et al., 2006). Managing the perception of value was related to ensuring strategic development, labelling it strategic value. The three dimensions are briefly explained in Table 4.

Table 4. Dimensions of value types

\begin{tabular}{llll}
\hline Value type & Characteristics & Example & Source \\
\hline Transformational & $\begin{array}{l}\text { Intended effects of changes } \\
\text { from initiatives }\end{array}$ & $\begin{array}{l}\text { New capabilities for delivering } \\
\text { cultural content } \\
\text { Empowerment }\end{array}$ & Gregor et al. (2006) \\
Emergent & $\begin{array}{l}\text { Unanticipated impacts that } \\
\text { evolve from the course of } \\
\text { events }\end{array}$ & $\begin{array}{l}\text { Collaborative capabilities } \\
\text { Creation of networks }\end{array}$ & $\begin{array}{l}\text { Mintzberg and Waters } \\
\text { (1985); Ang et al. } \\
\text { (2015) }\end{array}$ \\
Strategic & $\begin{array}{l}\text { Long-term and high-level } \\
\text { value that might be intrinsic }\end{array}$ & $\begin{array}{l}\text { City brand awareness } \\
\text { Cultural awareness among } \\
\text { citizens }\end{array}$ & $\begin{array}{l}\text { Martinsuo and Killen } \\
\text { (2014) }\end{array}$ \\
\hline
\end{tabular}

Table 4 does not contain an exhaustive list, as there are many taxonomies of value: for example, seven types of value suggested by Ang et al. (2016), the four-by-four model suggested by Ouden (2012), and strategic value in several dimensions (Martinsuo and Killen, 2014). While strategic value and transformational value are relatively well described in the literature, emergent value is relatively obscure. It follows the line of thought that contexts change and the environment reacts, and some outcomes will be emerging (Mintzberg and Waters, 1985).

The findings from this study suggest that transformational value and strategic value may cover both intrinsic and instrumental value. Value is instrumental because executing the $\mathrm{ECoC}$ brought tourists to the region and was expected to lead to increased wealth. Simultaneously, the legacy of the program was expected to create value for the public sphere in the longer term through a stronger cultural sector in the region surrounding Aarhus. 


\section{Decision making logics}

The three themes for value creation in the program and associated dimensions of value were established in a very complex environment, and the level of complexity was a recurring theme in interview data. The case was subject to very high uncertainty and ambiguity, making it difficult to apply value management approaches that have a defined product and existing customers with identifiable profiles (Thiry, 2002). The ECoC had neither product nor customers; the program was being developed and the public as a user group was highly heterogeneous. Artistic programming based on available skills was one part of the solution to managing the program. The findings from this study suggest that traditional project management ends-in-view logic was combined with other logics. Thiry (2015) noted that entrepreneurial methods can be applied for program management; this study concurred with this view and applied an effectual perspective (Sarasvathy, 2001) adapted to the project domain (Nguyen, 2015) in the analysis.

The nature of the setting and the types of decisions required in this case study demonstrate affinity with the four dimensions of effectuation:

1) Means-driven: The Aarhus 2017 bid was created based on a range of workshops, including SWOT analyses, focusing on the means at hand. Yet, after being nominated ECoC and taking on the management team, it became apparent that the bid could require a budget of more than $€ 125$ million, whereas they had estimated a budget of only $€ 66$ million. They needed therefore to focus on means in terms of funds at hand. In parallel there was also a strong causal drive for two reasons: first, the EU considered the bid book as a de facto contract (note that the first bid was submitted in September 2011 for a year of events and activities starting January 2017) and, second, because the municipalities were promised a return on investment of at least one to one.

2) Affordable loss-focused: Funding artists was partly based on the affordable loss effectual principle, recognizing and managing the potential for loss. For example, it was expected that not all artists who received funding be able to deliver the expected content during 2017, and 
this resulted in changes to the program. This is an example of effectuation being used to handle uncertainty in a strategic decision about developing a program in advance, recognizing that there were risks involved, and that a degree of 'affordable loss' may occur.

3) Partnering: Being an EU initiative, and also due to the public setting, overall the program was not market driven. The municipalities initially competed with each other, aiming to benefit individually from the ECoC and not give away any resources. In time, the power of partnerships became apparent to the participating municipalities and the ongoing value of the collaborations formed a major benefit from the ECoC.

4) Leveraging contingencies: ECoCs are notorious for changes to the management, and this was the case during 2014, with two managers resigning. It was especially difficult when the program director left, but the management brought in knowledgeable manpower and made the best of the situation.

Looking back at the three value creation themes identified - collaboration, coordination, and perception - it is notable that the ECoC did not follow traditional and causative ends-in-view logic for funding projects and carrying out activities. The emphasis on the value of collaboration created by the program recognizes the synergies of combining capabilities in line with the effectuation principle of partnering. Effectuation principles also align with the value of coordination. For example, active engagement with artists enabled management to set an entirely new course if a project hit a dead end; in this way the program was managed in a way that allowed leverage of contingencies for unexpected events, in addition to demonstrating the use of means-driven principles in shaping projects and the program. Various types of changes in the environment were used in communicating the narrative of Aarhus 2017, and thus unforeseen events were widely used in managing the perceptions.

Table 5 summarizes the links between value types and management themes, denoting whether they were primary or secondary. For example, in the context of Collaboration, the primary area of value 
creation was Emergent value, with a secondary area of value creation also evident in Strategic value.

Table 5. Value types and management themes in Aarhus 2017

\begin{tabular}{|l|l|l|l|}
\hline & Collaboration & Coordination & Perception \\
\hline Transformational & Secondary & Primary & Secondary \\
\hline Emergent & Primary & Secondary & Secondary \\
\hline Strategic & Secondary & Secondary & Primary \\
\hline
\end{tabular}

The types of value and management themes in Table 5 should be regarded as part of a contextual setting with a specific set of characteristics. The context provided by the ECoC program created an environment that lent itself to applying effectuation logic in decision making. It follows naturally from the theme 'Let's rethink' that the ECoC was concerned with change, but the specific impacts and the long-term legacy were not pre-defined. The guiding keywords for the content providers that is, the projects - were 'experimental', 'new connections' and 'create extraordinary experimental projects.' It was acknowledged and accepted that some projects would fail, primarily in the sense that some would not end up delivering quality content and others may not have been selected to deliver any content at all for the events during 2017. The program content consisted mostly of cultural events, and often the potential event was developed within the project. Thus, it was not pre-defined when funded by Aarhus 2017, and the output was defined by the resources and competences, in line with effectual decision logic. This is in contrast with traditional project logic, where ends are in focus and failures are not welcome.

\section{Discussion and implications}

The investigation into how value is created and managed in a program of cultural projects highlighted three primary themes that reveal different levels of intent, temporality, and subjectivity. Focusing on value creation in a program of cultural projects has provided a perspective that 
supported the emergence of non-financial themes. The analysis suggests that such themes are also important in the commercial sector, but often such themes are not recognized or focused upon because of the strong emphasis on financial and 'hard' measures. The first part of the discussion summarizes the three themes observed in this study and explores ways in which each may also relate to other environments, including the commercial sector. The discussion then considers how an alternative logic based on effectuation can be applied to the types of challenges exhibited in the ECoC case, especially in managing uncertainty and ambiguity in projects and programs.

\section{Relating value creation themes to the commercial sector}

The development of collaborative capabilities created through the ECoC was one of the larger and longer term types of value created; the collaborative value extended beyond Aarhus 2017 into the future. The creation of value through the development of long-term collaborative capabilities is one of the expected benefits from a program such as the ECoC, yet the concept is difficult to measure and so difficult to use for justifying the project or gaining political or public support. However, findings from this study suggest that efforts to identify and measure the value of collaborative capability development could improve planning and decision making. This is particularly relevant in commercial environments where collaborative capability is more important than ever (shown through the increasing use of open innovation approaches and alliances, for example), but is rarely acknowledged as a 'value' that can be created through a project or program. This study suggests that organizations in both commercial and non-commercial environments may benefit from recognizing the high impact and lasting contributions made possible by improved collaborative capability, and from incorporating such considerations when making decisions.

The second theme, value in coordination, represents a purposeful intention to coordinate across projects to provide diversity in the program. This diversity value is represented in this study by qualitative measures such as the breakdown of programs for different age groups, or the spread of projects representing different media, or the variety of locations for the program. While these 
measurements are relatively easy to record and communicate, they are a proxy for the perceived value; the reason coordination and balance are considered important is that it is expected that diversity will enable a high percentage of the population to value the ECoC. A positive public perception and a high degree of participation are major indicators of a successful ECoC.

In commercial environments, coordinating for diversity is already strongly exhibited in PPM literature and frameworks. The importance of balance across a program or portfolio of new products, for example, provides a way to manage risk by balancing low risk and short-term projects with more radical longer term and riskier projects. Similarly, the balance of projects across geographic areas in a commercial program aims to engage and address a wider range of employees and customers. In these commercial environments, balancing for diversity is associated with better success (usually measured in financial terms) of the resulting products (Cooper et al., 2001; Killen et al., 2008). In the commercial world, as in the program studied, the direct value creation from projects lies in the future and may be difficult to estimate or measure. However, this study emphasizes that value in coordination is important for program or portfolio value creation, and that ensuring diversity in decision making has benefits in both commercial and cultural environments.

The final theme is the unexpected 'value in perception.' The subjectivity, complexity, and the role of external influences such as the media on the perception of value are reflected in this third theme. From a program or PPM perspective, with its roots in the commercial world, it can seem controversial to suggest that 'perception of value' represent actual value. There can be a feeling that perceived value could be an illusion, that there may not be any underlying value after all. However, it is often noted that 'value is in the eyes of the beholder,' and that each individual has their own perception of what is valuable. This study found that the perceptions of value across the end users became important for value creation by the cultural program, and that due to the level of importance much effort was spent on managing stakeholder perceptions of value. There is some evidence that value perceptions are also important when managing a program in a commercial environment 
(brand perception and goodwill, for example); however, the creation of program value in such environments is usually expected to be demonstrated in hard measures such as financial performance, market penetration, or patents. In the absence of many hard measures of value, the importance of 'perceived value' has emerged in this study. The case of Aarhus 2017 also demonstrates the importance of managing the stakeholder perception of value - and how the media and communications related to the program must be managed to ensure that value is created. In commercial environments, the importance of considering perceived value and managing media and communications has not been illustrated in program and portfolio management research. However, such organizations often do recognize perceived value, and they invest in media and communications initiatives. Value will also be perceived in commercial settings, whether business managers recognize that perspective or not (Vatin, 2013). This study of value creation in a cultural program suggests that consideration of perceived value creation is could enhance PPM decision making in commercial organizations.

\section{Effectuation logic in projects and programs}

The importance of context is highlighted in the findings about the application of effectuation and causation logics to program management practices. The cultural and public context in this study provided a contrasting perspective from that found in most traditional commercial contexts and offered a rich environment for observing the use of effectuation logic alongside causal logic. This study supports the work of Reymen et al. (2015) and suggests that, instead of a dichotomous perspective (where projects are managed by either effectuation logic or causal logic), the two logics may be used in a variety of combinations depending on the decision context. 


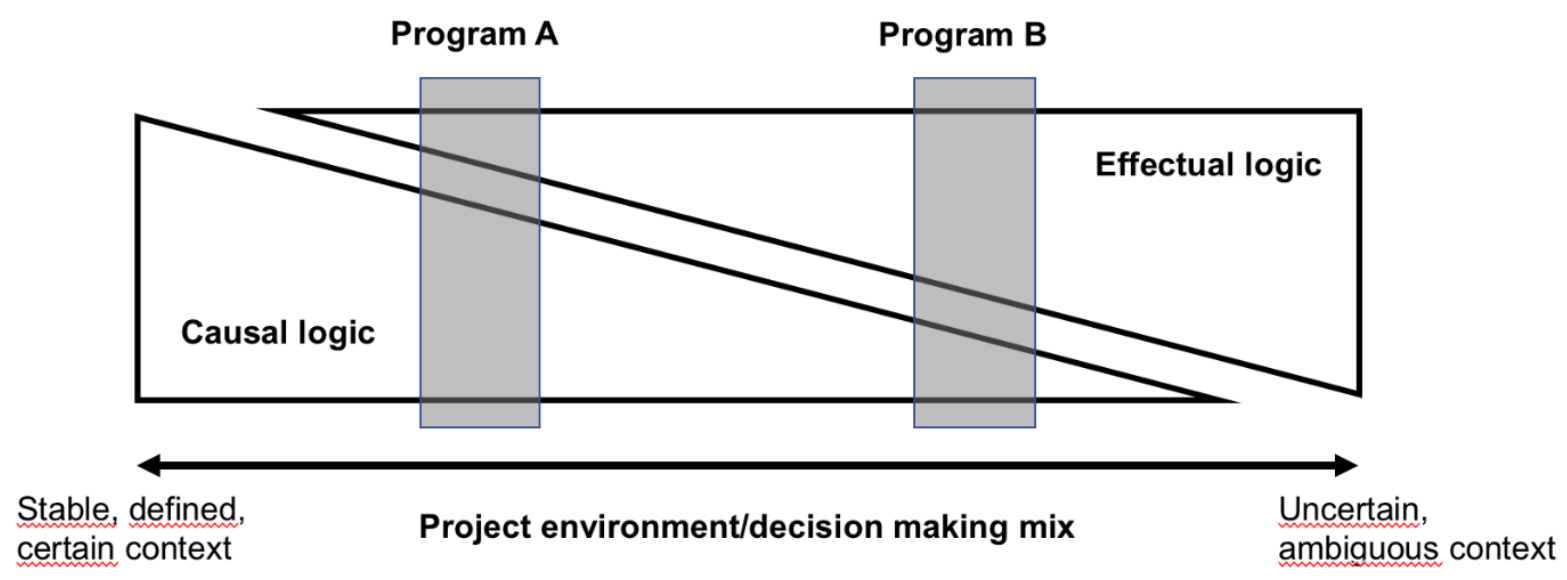

The findings suggest a concept of an effectuation-causation decision logic continuum, with pure effectuation at one end, and pure causation at the other, and many environments with a mix of both where one or the other decision logics dominate. Figure 2 illustrates such a continuum for project and program decision making to align the logic mix with the context. Context is also central in the model offered by Reymen et al. (2015) that links contextual factors with entrepreneurial decisionmaking aspects, including the type of logic. Focusing on the decision-making logic, this model is designed to be simple and generic and to emphasize the continuum of the degree of each logic and its relationship to the continuum of levels of uncertainty in projects. For example, Program A uses largely causal approaches, but some effectuation logic is evident - this might be a fairly standard program environment without much change and uncertainty. Program B, in contrast, employs primarily effectual logic - suited for its environment which may be closer to entrepreneurial situations or exploratory projects with e.g. uncertain outcomes or discovery (Lenfle, 2008; Loch et al., 2011).

Causation principles are readily identified in classical project management (Svejvig and Andersen, 2015) and in the task perspective (Andersen, 2008; Winter and Szczepanek, 2009). Effectuation principles may become similarly aligned with concepts proposed for rethinking project 
management: learnability, complexity, and uncertainty (Svejvig and Andersen, 2015). Concepts from entrepreneurship such as effectuation are particularly suited for advancing research in project, program, and portfolio management due to the coherence between the fields (Kuura et al., 2014; Lindgren and Packendorff, 2003). This study suggests that effectual logic can be relevant in both projects and programs; indeed, effectuation can be particularly relevant for program management (Sarasvathy and Venkataraman, 2011) due to the higher degree of uncertainty and ambiguity across the program level.

\section{Implications for practice}

Project practitioners who find that classical projects approaches do not fit with complex, uncertain, or ambiguous environments may find this illustration of a continuum of effectual and causal decision-making logic useful. By considering where their project fits on the continuum, practitioners may be able to tailor training and consider methods beyond the traditional project management toolbox. Practitioners, such as policy makers, may benefit from considering a contingent approach to the application of decision logics and management methods based on their understanding of how entrepreneurial projects with unknown ends (Sarasvathy and Venkataraman, 2011) are distinguished from traditional projects.

The theme of emergent value could be taken to suggest, provocatively, that project value can develop from what some will regard as pure coincidence. On the contrary, the findings from this study indicate that priming practitioners to spot the potential for unanticipated value creation early might enable them to nurture it and create more value from emergent sources, in a manner similar to the 'Opportunity exploitation' identified by Eskerod et al. (2018). This thinking also aligns with the counterintuitive concept of 'planned emergence' (Kopmann et al., 2017) which proposes benefits from project management approaches that identify, nurture and steer emergent strategies to take advantage of opportunities in changeable environments. 
Collaboration provides multiple benefits for practice including, but not limited to, the improved ability to apply for funding. In project environments, value is best developed through collaborative arrangements that are able to integrate the specific tasks of a project or program. The findings from this study encourage practitioners to establish the important integration mechanisms that will support collaborations across multiple organizations.

\section{Limitations}

This study is an explorative endeavor in Denmark after a reform of the public sector and may not represent other contexts. Future research is recommended to explore collaboration, coordination, and perception value creation in other contexts including commercial contexts. The synergies in the creative industry in a small internationally oriented country might be different from a large country, with a greater diversity and having minorities that are bigger in absolute numbers. As each ECoC is unique in terms of context, approach, and program of activities, it would be recommended to conduct further studies of public programs, perhaps other European Capitals of Culture, for elaborating on managing holistic value creation and coping with ambiguity and uncertainty.

The research reported in this paper does not cover the entire length of the Aarhus 2017 ECoC; rather, it is a study of the time until the peak of events taking place in 2017. The long-term effects, the so-called legacy, and other major societal changes were not evaluated in this study and could be the topic for further research. In addition, future studies may benefit from including a wider base of stakeholders associated with creating and evaluating value in Aarhus 2017; this study was limited to interviews with managers and employees at the Aarhus 2017 secretariat.

\section{Conclusion}

This study answers the call for further in-depth research into value creation in non-commercial environments. A public program has provided a rich environment for the scrutiny of value creation in ways beyond those applied in commercial settings, generating findings to challenge and extend 
the established concepts of value and success in projects and programs. The research reported in this paper illustrates how the management of a program of cultural projects created strategic, emergent, and transformational value, and suggests that these types of value are important in commercial and other settings. The findings highlight the long-term structural value from the creation of collaborative capability through a program; the ways that coordination of a program contributes to value creation; and the value placed on the perception of value that leads to careful monitoring and management of communication.

The identified themes served as the basis for exploring the use of effectuation and causations decision logics first identified in the field of entrepreneurship. These contrasting logics are shown to help manage uncertainty and ambiguity in projects and programs. Both types of decision logic can be effectively combined to best support decision making in projects or programs. To better understand the context and the balance of both types of decision logic, a project or program environment could be positioned along an effectuation-causation decision logic continuum to illustrate the mixing of both logics.

Management of projects, programs and portfolios in both non-commercial and commercial project contexts is often challenging due to complexity, uncertainty, and ambiguity that are not best managed through traditional causal project approaches. A unique non-commercial environment enabled the authors to distil findings about the creation of value beyond those emphasized in commercial settings - findings that also have relevance in commercial environments. The findings support the development of distinctive project and program practices that harness the power of both effectuation and causation decision logics and enhance decision making processes to improve the ability to create multiple types of value through projects and programs in uncertain environments. 


\section{Acknowledgments}

The research was funded by rethinkIMPACTS 2017, a strategic collaboration project between the

Aarhus 2017 foundation and Aarhus University conducting a formative and research-based

evaluation of Aarhus 2017.

\section{References}

AARHUS 2017 2012. Aarhus 2017 Candidate European Capital of Culture 2017: Final application. In: DAVIS, T. (ed.). Aarhus, Denmark: Kulturforvaltningen Aarhus Kommune.

AARHUS 2017 2015. Strategic Business Plan. Aarhus, Denmark: Aarhus 2017, European Capital of Culture.

AARHUS 2017 2016. Q \& A - Europæisk Kulturhovedstad Aarhus 2017. Aarhus.

ANDERSEN, E. S. 2008. Rethinking project management: An organisational perspective, Essex, England, FT Prentice Hall.

ANG, K., KILLEN, C. \& SANKARAN, S. Unanticipated value creation: Sensemaking and the value spectrum in partnership projects. 12th IRNOP (International Research Network on Organizing by Projects), June 22-24 2015 London, UK.

ANG, K. C. S., SANKARAN, S. \& KILLEN, C. P. 2016. 'Value for Whom, by Whom': Investigating Value Constructs in Non-Profit Project Portfolios. Project Management Research and Practice, 3, 5038.

AREND, R. J., SAROOGHI, H. \& BURKEMPER, A. 2015. EFFECTUATION AS INEFFECTUAL? APPLYING THE 3E THEORY-ASSESSMENT FRAMEWORK TO A PROPOSED NEW THEORY OF ENTREPRENEURSHIP. Academy of Management Review, 40, 630-651.

ARTTO, K., AHOLA, T. \& VARTIAINEN, V. 2016. From the front end of projects to the back end of operations: Managing projects for value creation throughout the system lifecycle. International Journal of Project Management, 34, 258-270.

BARCLAY, C. \& OSEI-BRYSON, K.-M. 2009. Toward a more practical approach to evaluating programs: The multi-objective realization approach. Project Management Journal, 40, 74-93.

BARNEY, J. 1991. Firm Resources and Sustained Competitive Advantage. Journal of Management, 17, 99120.

BENINGTON, J. 2009. Creating the Public In Order To Create Public Value? International Journal of Public Administration, 32, 232-249.

BENINGTON, J. 2011. From private choice to public value. In: BENINGTON, J. \& MOORE, M. H. (eds.) Public value: Theory and practice. New York, NY: Palgrave Macmillan.

BOWEN, G. A. 2009. Document Analysis as a Qualitative Research Method. Qualitative Research Journal, 9, 27-40.

BRADLEY, G. 2010. Benefit Realisation Management, Farnham, Gower.

BRETTEL, M., MAUER, R., ENGELEN, A. \& KÜPPER, D. 2012. Corporate effectuation: Entrepreneurial action and its impact on R\&amp;D project performance. Journal of Business Venturing, 27, 167-184.

BRYSON, J., SANCINO, A., BENINGTON, J. \& SØRENSEN, E. 2016. Towards a multi-actor theory of public value co-creation. Public Management Review, 1-15.

CHANDLER, G. N., DETIENNE, D. R., MCKELVIE, A. \& MUMFORD, T. V. 2011. Causation and effectuation processes: A validation study. Journal of Business Venturing, 26, 375-390.

CHARMAZ, K. 2014. Constructing grounded theory, London, SAGE Publications.

COLE, M. \& PARSTON, G. 2006. Unocking Public Value: A New Model For Achieving High Performance In Public Service Organizations, Hoboken, NJ, John Wiley \& Sons.

COOPER, R. G., EDGETT, S. J. \& KLEINSCHMIDT, E. J. 2001. Portfolio management for new product development: Results of an industry best practices study. $R$ and D Management, 31, 361-381. 
CROSSICK, G. \& KASZYNSKA, P. 2016. Understanding the value of arts \& culture. The AHRC cultural value project. London: AHRC. Wiltshire, UK.

DUBOIS, A. \& GADDE, L.-E. 2014. "Systematic combining"-A decade later. Journal of Business Research, 67, 1277-1284.

EDMONDSON, A. C. \& MCMANUS, S. E. 2007. Methodological fit in management field research. Academy of management review, 32, 1246-1264.

ESKEROD, P., ANG, K. \& ANDERSEN, E. S. 2018. Increasing project benefits by project opportunity exploitation. International Journal of Managing Projects in Business, 11, 35-52.

EUROPEAN STANDARD 12973-2000 2000. Value Management.

EUROPEAN UNION 2015. European capitals of culture - 30 years. Luxembourg: Publications Office of the European Union.

FISHER, G., KOTHA, S. \& LAHIRI, A. 2016. Changing with the Times: An Integrated View of Identity, Legitimacy, and New Venture Life Cycles. Academy of Management Review, 41, 383-409.

FOG, K., BUDTZ, C., MUNCH, P. \& BLANCHETTE, S. 2010. Storytelling: Branding in practice, Frederiksberg C, DK, Samfundslitteratur Press.

GARCIA, B., MELVILLE, R. \& COX, T. 2010. Creating an impact: Liverpool's experience as European Capital of Culture. Liverpool: Impacts 08.

GERALDI, J. \& SÖDERLUND, J. 2016. Project studies and engaged scholarship: Directions towards contextualized and reflexive research on projects. International Journal of Managing Projects in Business, 9, 767-797.

GRANOVETTER, M. S. 1973. The strength of weak ties. American journal of sociology, 1360-1380.

GREGOR, S., MARTIN, M., FERNANDEZ, W., STERN, S. \& VITALE, M. 2006. The transformational dimension in the realization of business value from information technology. The Journal of Strategic Information Systems, 15, 249-270.

HANSEN, L. E. \& LAURSEN, M. 2015. From applicant to designated European Capital of Culture. International Journal of Managing Projects in Business, 8, 715-731.

HORNER, L. \& HAZEL, L. 2005. Adding public value, London, Work Foundation.

HUFF, A. S. 2016. Project Innovation: Evidence-Informed, Open, Effectual, and Subjective. Project Management Journal, 47, 8-25.

JUGDEV, K. \& MÜLLER, R. 2005. A RETROSPECTIVE LOOK AT OUR EVOLVING UNDERSTANDING OF PROJECT SUCCESS. Project Management Journal, 36, 19-31.

KELLY, G., MULGAN, G. \& MUERS, S. 2002. Creating Public Value: An analytical framework for public service reform. London, UK: Discussion paper prepared by the Cabinet Office Strategy Unit.

KILLEN, C. P., HUNT, R. A. \& KLEINSCHMIDT, E. J. 2008. Project portfolio management for product innovation. International Journal of Quality and Reliability Management, 25, 24-38.

KOPMANN, J., KOCK, A., KILLEN, C. P. \& GEMUENDEN, H. G. 2015. Business Case Control in Project Portfolios-An Empirical Investigation of Performance Consequences and Moderating Effects. IEEE Transactions on Engineering Management, 62, 529-543.

KOPMANN, J., KOCK, A., KILLEN, C. P. \& GEMUENDEN, H. G. 2017. The role of project portfolio management in fostering both deliberate and emergent strategy. International Journal of Project Management, 35, 557-570.

KUURA, A., BLACKBURN, R. A. \& LUNDIN, R. A. 2014. Entrepreneurship and projects-Linking segregated communities. Scandinavian Journal of Management, 30, 214-230.

KVALE, S. \& BRINKMANN, S. 2009. Interviews: Learning the craft of qualitative research interviewing, Sage Publications, Incorporated.

LAURSEN, M. 2018. Project Networks as Constellations for Value Creation. Project Management Journal, 49, 56-70.

LAURSEN, M. \& SVEJVIG, P. 2016. Taking stock of project value creation: A structured literature review with future directions for research and practice. International Journal of Project Management, 34, 736-747.

LENFLE, S. 2008. Exploration and project management. International Journal of Project Management, 26, 469-478.

LEPAK, D. P., SMITH, K. G. \& TAYLOR, S. M. 2007. Value creation and value capture: A multilevel perspective. Academy of Management Review, 32, 180-194. 
LINDGREN, M. \& PACKENDORFF, J. 2003. A project-based view of entrepreneurship: Towards actionorientation, seriality and collectivity. In: STEYAERT, C. \& HJORTH, D. (eds.) Entrepreneurship: New Movements. Cheltenham, UK: Edward Elgar Publishing.

LOCH, C. H., DEMEYER, A. \& PICH, M. 2011. Managing the unknown: A new approach to managing high uncertainty and risk in projects, John Wiley \& Sons.

LOVE, P. E. D., MATTHEWS, J., SIMPSON, I., HILL, A. \& OLATUNJI, O. A. 2014. A benefits realization management building information modeling framework for asset owners. Automation in Construction, 37, 1-10.

LYCETT, M., RASSAU, A. \& DANSON, J. 2004. Programme management: a critical review. International Journal of Project Management, 22, 289-299.

MARTELA, F. 2015. Fallible inquiry with ethical ends-in-view: A pragmatist philosophy of science for organizational research. Organization Studies, 36, 537-563.

MARTINSUO, M. \& KILLEN, C. P. 2014. Value Management in Project Portfolios: Identifying and Assessing Strategic Value. Project Management Journal, 45, 56-70.

MAYLOR, H., BRADY, T., COOKE-DAVIES, T. \& HODGSON, D. 2006. From projectification to programmification. International Journal of Project Management, 24, 663-674.

MERRIAM-WEBSTER. 2016. "Cost" [Online]. Merriam-Webster.com. Available: http://www.merriamwebster.com/dictionary/cost [Accessed 2016-06-20 2016].

MESKENDAHL, S. 2010. The influence of business strategy on project portfolio management and its success - A conceptual framework. International Journal of Project Management, 28, 807-817.

MINTZBERG, H. \& WATERS, J. A. 1985. Of strategies, deliberate and emergent. Strategic Management Journal, 6, 257-272.

MOORE, M. H. 1995. Creating public value: Strategic management in government, Cambridge, Massachusetts, Harvard University Press.

MOORE, M. H. 2000. Managing for Value: Organizational Strategy in For-Profit, Nonprofit, and Governmental Organizations. Nonprofit and Voluntary Sector Quarterly, 29, 183-208.

MOORE, M. H. 2013. Recognizing Public Value, Harvard University Press.

MORRIS, P. 2013. Reconstructing Project Management, Chichester, UK, Wiley Blackwell.

MYERS, M. D. 2009. Qualitative research in business and management, Los Angeles, SAGE.

NGUYEN, N. M. 2015. Effectuation as a decision-making approach in project portfolio management. 12th International Conference of the International Research Network on Organizing by Projects. London.

NGUYEN, N. M., KILLEN, C. P., KOCK, A. \& GEMÜNDEN, H. G. 2018. The use of effectuation in projects: The influence of business case control, portfolio monitoring intensity and project innovativeness. International Journal of Project Management, 36, 1054-1067.

NÄSHOLM, M. H. \& BLOMQUIST, T. 2015. Co-creation as a strategy for program management. International Journal of Managing Projects in Business, 8, 58-73.

O'FLYNN, J. 2007. From New Public Management to Public Value: Paradigmatic Change and Managerial Implications. Australian Journal of Public Administration, 66, 353-366.

OUDEN, E. D. 2012. Innovation design: Creating value for people, organizations and society, London, United Kingdom, Springer-Verlag London.

PAGE, S. B., STONE, M. M., BRYSON, J. M. \& CROSBY, B. C. 2015. PUBLIC VALUE CREATION BY CROSS-SECTOR COLLABORATIONS: A FRAMEWORK AND CHALLENGES OF ASSESSMENT. Public Administration, 93, 715-732.

PANG, M.-S., LEE, G. \& DELONE, W. H. 2014. IT resources, organizational capabilities, and value creation in public-sector organizations: a public-value management perspective. J Inf technol, 29, 187-205.

PATTON, M. Q. 2002. Qualitative Research \& Evaluation Methods, Thousand Oaks, Sage Publications Inc.

PELLEGRINELLI, S. 1997. Programme management: organising project-based change. International Journal of Project Management, 15, 141-149.

PELLEGRINELLI, S. 2011. What's in a name: Project or programme? International Journal of Project Management, 29, 232-240.

PORTER, M. E. 1985. Competitive advantage : Creating and sustaining superior performance, New York, The Free Press.

PRAHALAD, C. \& HAMEL, G. 1990. The core competence of the corporation. Harvard Business Review. 
READ, S., DEW, N., SARASVATHY, S. D., SONG, M. \& WILTBANK, R. 2009. Marketing Under Uncertainty: The Logic of an Effectual Approach. Journal of Marketing, 73, 1-18.

REYMEN, I. M. M. J., ANDRIES, P., BERENDS, H., MAUER, R., STEPHAN, U. \& VAN BURG, E. 2015. Understanding Dynamics of Strategic Decision Making in Venture Creation: A Process Study of Effectuation and Causation. Strategic Entrepreneurship Journal, 9, 351-379.

RICHARDS, D. 1996. Elite Interviewing: Approaches and Pitfalls. Politics, 16, 199-204.

SARASVATHY, S. D. 2001. CAUSATION AND EFFECTUATION: TOWARD A THEORETICAL SHIFT FROM ECONOMIC INEVITABILITY TO ENTREPRENEURIAL CONTINGENCY. Academy of management review, 26, 243-263.

SARASVATHY, S. D. 2008. Effectuation: Elements of entrepreneurial expertise, Edward Elgar Publishing.

SARASVATHY, S. D. \& VENKATARAMAN, S. 2011. Entrepreneurship as Method: Open Questions for an Entrepreneurial Future. Entrepreneurship Theory and Practice, 35, 113-135.

SCHRYEN, G. 2013. Revisiting IS business value research: What we already know, what we still need to know, and how we can get there. European Journal of Information Systems, 22, 139-169.

SPRADLEY, J. P. 1980. Participant observation, New York, NY, Wadsworth Thomson Learning.

SVEJVIG, P. \& ANDERSEN, P. 2015. Rethinking project management: A structured literature review with a critical look at the brave new world. International Journal of Project Management, 33, 278-290.

THIRY, M. 2002. Combining value and project management into an effective programme management model. International Journal of Project Management, 20, 221-227.

THIRY, M. 2015. Program management, Farnham, UK, Gower Publishing Limited.

TOOR, S. U. R. \& OGUNLANA, S. O. 2010. Beyond the 'iron triangle': Stakeholder perception of key performance indicators (KPIs) for large-scale public sector development projects. International Journal of Project Management, 28, 228-236.

VAN DE VEN, A. H. 2007. Engaged scholarship: A guide for organizational and social research, Oxford, United Kingdom, Oxford University Press.

VATIN, F. 2013. Valuation as evaluating and valorizing. Valuation Studies, 1, 31-50.

VEREECKE, A., PANDELAERE, E., DESCHOOLMEESTER, D. \& STEVENS, M. 2003. A classification of development programmes and its consequences for programme management. International Journal of Operations \& Production Management, 23, 1279-1290.

WILLIAMS, D. \& PARR, T. 2004. Enterprise programme management, New York, NY, PALGRAVE MACMILLAN.

WINTER, M., ANDERSEN, E. S., ELVIN, R. \& LEVENE, R. 2006. Focusing on business projects as an area for future research: An exploratory discussion of four different perspectives. International Journal of Project Management, 24, 699-709.

WINTER, M. \& SZCZEPANEK, T. 2008. Projects and programmes as value creation processes: A new perspective and some practical implications. International Journal of Project Management, 26, 95103.

WINTER, M. \& SZCZEPANEK, T. 2009. Images of projects, Farnham, Gower.

WÅHLIN, N., KAPSALI, M., HARRYSON NÄSHOLM, M. \& BLOMQUIST, T. 2016. Urban Strategies for Culture-Driven Growth: Co-Creating a European Capital of Culture. 